\title{
Lee Silverman Voice Treatment to Improve Speech in Parkinson's Disease: A Systemic Review and Meta-Analysis
}

\author{
Tingting Pu, ${ }^{1,2}$ Min Huang, ${ }^{3}$ Xiangyu Kong, ${ }^{2}$ Meng Wang, ${ }^{2}$ Xiangling Chen, ${ }^{2}$ Xixi Feng, \\ Changyou Wei, ${ }^{2}$ Xiechuan Weng $\mathbb{D},{ }^{4}$ and Fan $\mathrm{Xu} \mathbb{D}^{2}$ \\ ${ }^{1}$ School of Pharmacy, Dali University, Yunnan 671000, Dali, China \\ ${ }^{2}$ Department of Public Health, Chengdu Medical College, Sichuan 610500, Chengdu, China \\ ${ }^{3}$ Department of Physiology, Chengdu Medical College, Sichuan 610500, Chengdu, China \\ ${ }^{4}$ Beijing Institute of Basic Medical Sciences, Beijing 100850, China
}

Correspondence should be addressed to Xiechuan Weng; wengxc2000@163.com and Fan Xu; xufan@cmc.edu.cn

Tingting Pu, Min Huang, and Xiangyu Kong contributed equally to this work.

Received 13 October 2021; Revised 7 December 2021; Accepted 10 December 2021; Published 27 December 2021

Academic Editor: Carlo Colosimo

Copyright (C) 2021 Tingting Pu et al. This is an open access article distributed under the Creative Commons Attribution License, which permits unrestricted use, distribution, and reproduction in any medium, provided the original work is properly cited.

Background. Speech changes occur in the early stages of Parkinson's disease (PD) and cause communication difficulties, leading to social isolation. Lee Silverman voice treatment (LSVT) is a speech therapy approach designed to improve patients' language and voice capabilities. Objective. The effectiveness of the LSVT was compared with that of other speech interventions or no treatment to evaluate PD patients with dysarthria. Design. Systematic review with meta-analysis of randomized trials. Data Sources: PubMed, Embase, Cochrane Library, CNKI, and SinoMed library were searched from inception to December 2021 related to PD and LSVT. Method. Abstracts were screened and reviewed against the eligibility criteria (intervention group participants were PD assessed based on LSVT (LSVT Loud) and randomized control). Result. Ten randomized controlled trials were identified on speech symptoms in patients with PD. Compared with the respiratory therapy (RET) exercise, or no training group, a significant improvement was detected in the sound press level (SPL) after immediate treatment during the reading of vowel and rainbow passages and an increase in semitone standard deviation (STSD). Furthermore, the LSVT training significantly increased the participants' scores on unified Parkinson's disease rating scale (UPDRS-III) and speech intelligibility. Conclusion. This meta-analysis demonstrated the efficacy of LSVT in increasing vocal loudness and functional communication among individuals with PD. However, most studies included participants with mild-moderate PD. Thus, additional randomized controlled trials (RCTs) with large sample sizes are needed to validate the efficacy of LSVT in patients with different progressions of PD, including severe PD.

\section{Introduction}

Parkinson's disease (PD) is characterized by the loss of dopamine neurons, leading to motor and nonmotor dysfunction [1]. PD patients reached 5 million in the USA, affecting $1 \%$ of above 60-year-old population [2]. PD patients manifest motor symptoms, such as tremor, muscular rigidity, and bradykinesia, while speech disorders are one of the common nonmotor symptoms that make PD patients often experience a reduction in loudness, imprecise articulation, abnormal nasal resonance, voice and pitch, and prosody error symptoms [3]. Phonation is the essential interaction between humans and environments that undertakes human thought and mood [4]. In our previous studies, we have demonstrated that PD patients have head tremble, facial expressions, and speech disorders [5-7]. PD patients with speech disorders have difficulties in speaking or signaling their thoughts and intentions, which causes impairments in social interaction and communication accompanied by psychotic disorders.

Clinically, speech disorders are defined as hypophonia caused by respiration, vocal production, and articulation [8]. $\mathrm{PD}$ can be treated with surgical treatments, such as deep brain stimulation of the subthalamic nucleus (STN-DBS) proven to be an effective treatment for limb motor symptoms. However, 
the data suggest that bilateral STN-DBS (with or without medication) most often deteriorates speech functions that do not improve once the stimulation is turned off [9]. Studies have found that STN-DBS patients treated with Lee Silverman voice treatment (LSVT) had significant clinical improvement in VHI scores, voice, and speech [10]. In addition, the traditional drug treatment was administered, 1 or 2 drugs a day for a month, emphasizing to improve voice clarity and prosody to determine the correct position of phonemic phonation and produce language-specific phonemics $[11,12]$. It also increases the intermuscular coordination and intensity exercise of the tongue, chin, mouth, and other organs but has only modest effects on the prosodic aspects of parkinsonian speech [13]. Jan Rusz has expressed similar views; the long-term administration of dopamine in PD patients can stabilize the severity of speech disorder and improve speech performance [14].

\section{Methods}

2.1. Search Strategy. Two reviewers (Tingting $\mathrm{Pu}$ and Xinagyu Kong) independently searched the PubMed, Embase, Cochrane Library, CNKI, and SinoMed library databases up to December 2021, using various speech disorder-related words and $\mathrm{MeSH}$ terms in combination with $\mathrm{PD}$, irrespective of date, language, region, or publication type. MeSH search terms included PD. Free words included voice/speech therapy, voice/speech treatment, voice/speech training, voice/speech rehabilitation, or LSVT. The search was limited to published clinical studies.

2.2. Inclusion and Exclusion Criteria. Inclusion criteria were as follows: (1) All trial types are limited to randomized controlled trials (RCTs); (2) patients' age, sex, drug type, duration of illness, duration of treatment, and voice handicap index (VHI) were not limited, but only included the PD patients who met the UK Parkinson's disease society bank criteria; (3) intervention: LSVT; (4) control group: using other speech disorder treatments or no intervention measures; and (5) main outcomes include sound press level (SPL) and VHI, and the secondary outcomes consist of the semitone standard deviation (STSD), unified Parkinson's disease rating scale-III (UPDRS-III)-speech item score and speech intelligibility. The exclusion criteria were no outcomes described, no control groups, or animal experiments (Figure 1).

2.3. Data Extraction. Two authors (Tingting Pu and Xiangyu Kong) independently extracted the demographic data and treatment information, and the disagreements were resolved by a third author (Min Huang). The baseline information was extracted from 10 studies: the first author's name, year of publication, title, design type, study subjects (number, age, male/female ratio), disease degree, and length of the disease (Table 1). In addition, the intensity, course of treatment, and follow-up time were extracted from the intervention measures. The primary outcomes included the SPL and VHI, and the secondary outcomes consisted of the STSD, UPDRS-III, speech item score, and speech intelligibility.
2.4. Quality Assessment. The type of trial, allocation concealment, blinding of subjects, blinding of results, loss of follow-up bias, selection bias, and other biases were involved in assessing the methodological quality. The risk of bias was assessed using the Cochrane risk-of-bias assessment tool.

2.5. Statistical Analysis. The meta-analysis was performed with the statistical software review manager (version 5.4, $\mathrm{UK})$. We defined the mean, standard deviation (SD), and OR with 95\% confidence interval (CI) as the effect size. Heterogeneity was assessed by Cochrane's Q statistics (chisquare) or inverse variance $\left(I^{2}\right)$. If $I^{2}$ was $<50 \%$, and the $P$ value was $>0.1$, these studies could be considered homogeneous as assessed by a fixed-effects model; or else $I^{2} \geq 50 \%$, $P<0.10$, the random effect model was used for metaanalysis. When heterogeneity was high $\left(I^{2} \geq 50 \%, P<0.10\right)$, subgroup analysis was applied to analyze the sensitivity.

\section{Results}

3.1. Study Selection and Characteristics. A total of 10 articles were ruled out from 1624 references. The detailed information for literature screening was as follows (Figure 1). Table 1 summarizes the demographic data of 269 patients in the intervention group and 240 patients in the control group. Descriptive statistics were computed to identify the demographic information, including intervention, Hoehn-Yahr (HY) score, PD duration, age, sex, and outcomes (Table 1). In addition, the risk-of-bias was assessed using the Cochrane handbook based on published research and registration trials (Figures 2 and 3 ).

3.2. SPL Immediately after Treatment. We conducted four types of studies (LO Ramig 1995, LO Ramig 1996, LO Ramig 2001a, LO Ramig 2001b) to evaluate the efficacy of SPL. A total of 141 participants were tested with three voice tasks, and voice testing revealed a higher SPL level in the LSVT group $(7.36 \mathrm{~dB}, 95 \% \mathrm{CI}: 6.60-8.12, P<0.00001)$ than the control group, with high heterogeneity $\left(I^{2}=89 \%\right)$. After subgroup analyses, the SPL level increased during pronunciation vowel $(13.33 \mathrm{~dB}, 95 \% \quad \mathrm{CI}$ : 11.85-14.81, $P<0.00001)$, while reading of the rainbow passage $(6.67 \mathrm{~dB}$, 95\% CI: 5.38-7.97, $P<0.00001)$, the monologues $(3.93 \mathrm{~dB}$, 95\% CI: $2.71-5.14, P<0.00001$ ), and the heterogeneity was not significant across four studies (from $89 \%$ to $0 \%$ ) (Figure 4).

3.3. SPL for the Different times after Treatment. According to the different SPLs after treatment in the studies, the test time was divided into 1-6 months and 6-12 months. Compared with the control group, the LSVT group had an improved SPL score $5.19 \mathrm{~dB}$ (95\% CI: 3.23-7.15, $P<0.00001)$ after $1-6$ months (Figure 5(a)) and $3.88 \mathrm{~dB}$ (95\% CI: 2.60-5.16, $P<0.00001$ ) after $6-12$ months (Figure 5(b)). Four studies (L O Ramig 2001b, L O Ramig 2018, L O Ramig 1996, Geralyn Schulz 2021) reported that the higher SPL scores during pronunciation vowel, reading of the rainbow passage, 


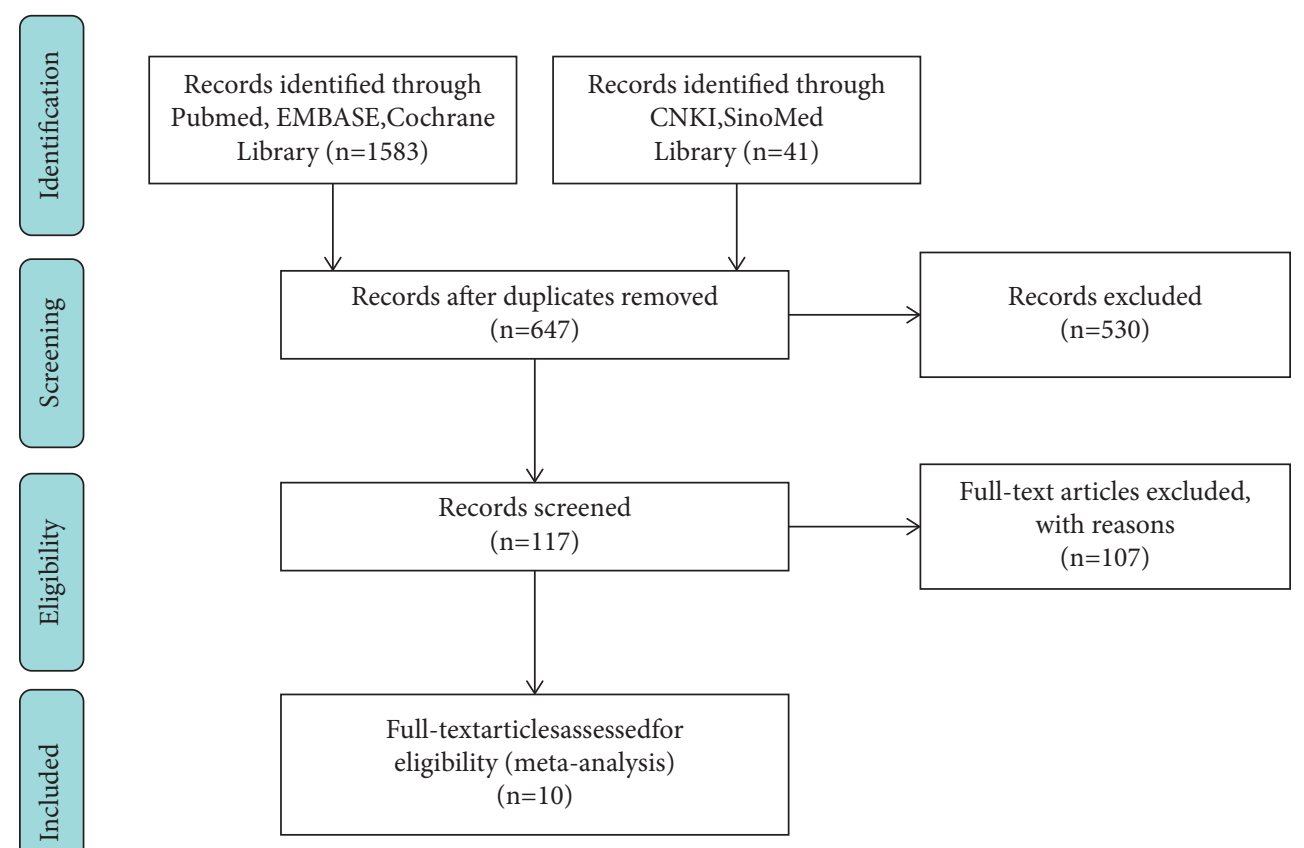

Figure 1: Flowchart displaying study selection.

and monologues were $8.03 \mathrm{~dB} \quad(95 \%$ CI: 6.25-9.82, $P<0.00001), 4.07 \mathrm{~dB}$ (95\% CI: $2.45-5.69, P<0.00001)$, and $2.20 \mathrm{~dB}$ (95\% CI: 0.81-3.59, $P=0.002)$, respectively, after 1-6 months. In addition, three studies (L O Ramig 2001a, L O Ramig 2018, LO Ramig 1996) reported an increased SPL score during pronunciation vowel, reading of the rainbow passage, and monologues $6.31 \mathrm{~dB}$ (95\% CI: 3.54-9.07, $P<0.00001), 3.37 \mathrm{~dB}$ (95\% CI: $1.42-5.32, P=0.0001)$, and $3.04 \mathrm{~dB}$ (95\% CI: 0.90-5.19, $P=0.005)$, respectively, after 6-12 months (Figure 5(b)).

3.4. VHI Effect after Treatment. Four studies, Arezzo Saffarian 2019, Qi Wu 2020, Haiyu Tnag 2016, and Meifang Yang 2017, were included. Importantly, we found a decreased grade of VHI by the LSVT treatment $(-14.60,95 \%$ CI: -22.43 to $-6.77, P<0.00001)$ compared to the control (Figure 6).

3.5. STSD during a Reading of the Rainbow and Monologues. The STSD was described only in three studies (LO Ramig 1995, LO Ramig 1996, LO Ramig 2001a). Interestingly, we compared the score of STSD in patients with PD and controls and found that the LSVT improved the score during reading the rainbow passage $(0.30 \mathrm{~dB}, 95 \% \mathrm{CI}: 0.11-0.50$, $P=0.002$ ) (Figure 7(a)). However, no significant difference was detected during the monologues $(P=0.75)$ (Figure $7(\mathrm{~b})$ ).

3.6. UPDRS-III Speech Item Score. Patients with PD included in Qi Wu 2020, Haiyu Tang 2016, and Meifang Yang 2017 were subjected to a voice test. Compared to the control, the UPDRS-III speech item score was significantly reduced after the treatment $(-0.57,95 \% \mathrm{CI}:-0.88$ to $-0.26, P=0.0003)$ with significant heterogeneity $\left(I^{2}=75 \%\right)$ (Figure 8 ).

3.7. Speech Intelligibility Effect after Treatment. In this study, three studies (Haiyu Tang 2016, Meifang Yang 2017, and Qi $\mathrm{Wu} 2020$ ) of data were used to analyze speech intelligibility in patients. The current data indicated that LSVT improves the speech intelligibility of PD (16.54, 95\% CI: 11.35-21.72, $P<0.00001)$. However, the meta-analysis revealed significant heterogeneity $\left(I^{2}=77 \%\right)$ (Figure 9 ).

3.8. Sensitivity Analysis. Considerable heterogeneity $\left(I^{2}=75 \%\right)$ was observed after immediate treatment in the UPDRS-III speech item score. The leave-one-out sensitivity analysis revealed a decrease (from $75 \%$ to $0 \%$ ) in heterogeneity and UPDRS-III speech item score $(-0.41,95 \% \mathrm{CI}$ : -0.64 to $-0.19, P=0.0004$ ) when one study (Tang 2016) was excluded. Compared to the baseline data, interventions, and the evaluation of outcomes in Tang 2016, those in other studies in this meta-analysis were not considerably different. Therefore, the heterogeneity may be derived from systematic errors. In addition, heterogeneity $\left(I^{2}=92 \%\right)$ in the VHI was attributed to another study (Saffarian 2019). When this study was excluded, a decrease (from $92 \%$ to $0 \%$ ) and a reduction of the VHI score $(-10.50,95 \% \mathrm{CI}:-12.45$ to -8.45 , $P<0.00001)$ indicated that the heterogeneity was attributable to this study (Saffarian 2019).

\section{Discussion}

Speech changes occur in the early stages of PD and cause communication difficulties, leading to social isolation [15]. Typically, pharmacological and neurosurgical treatments are 


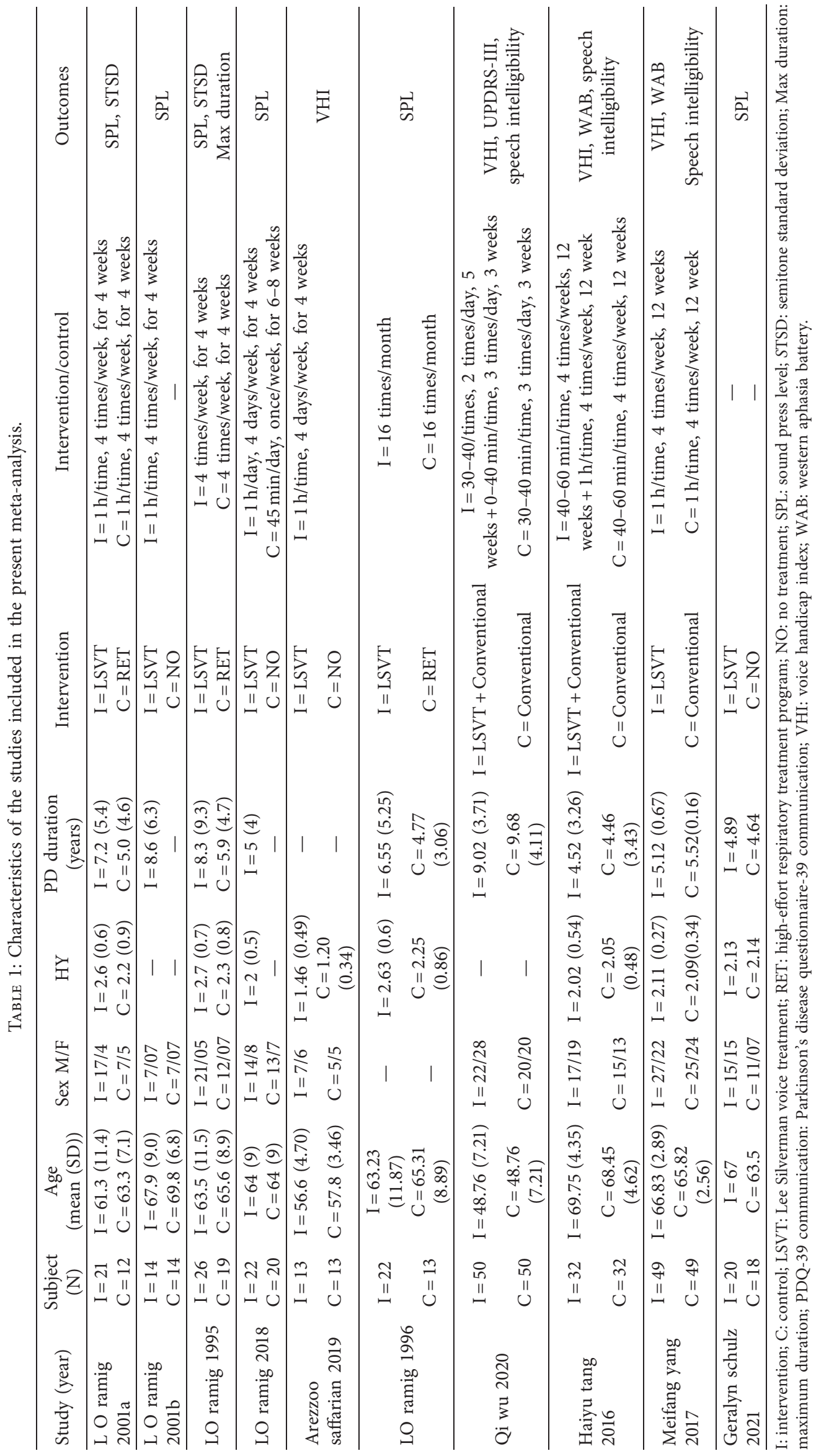




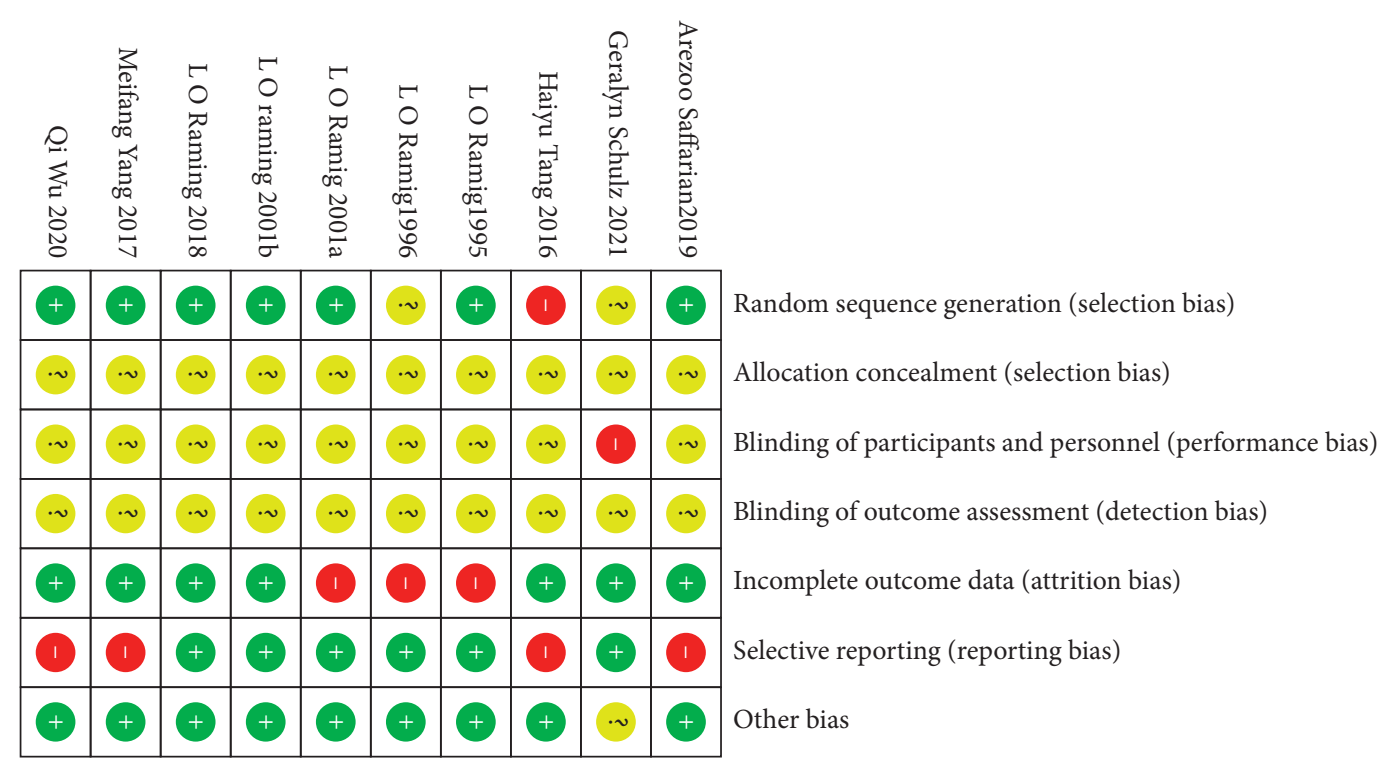

FIGURE 2: Risk-of-bias summary: a review of authors' judgments about each risk-of-bias item for each included study.

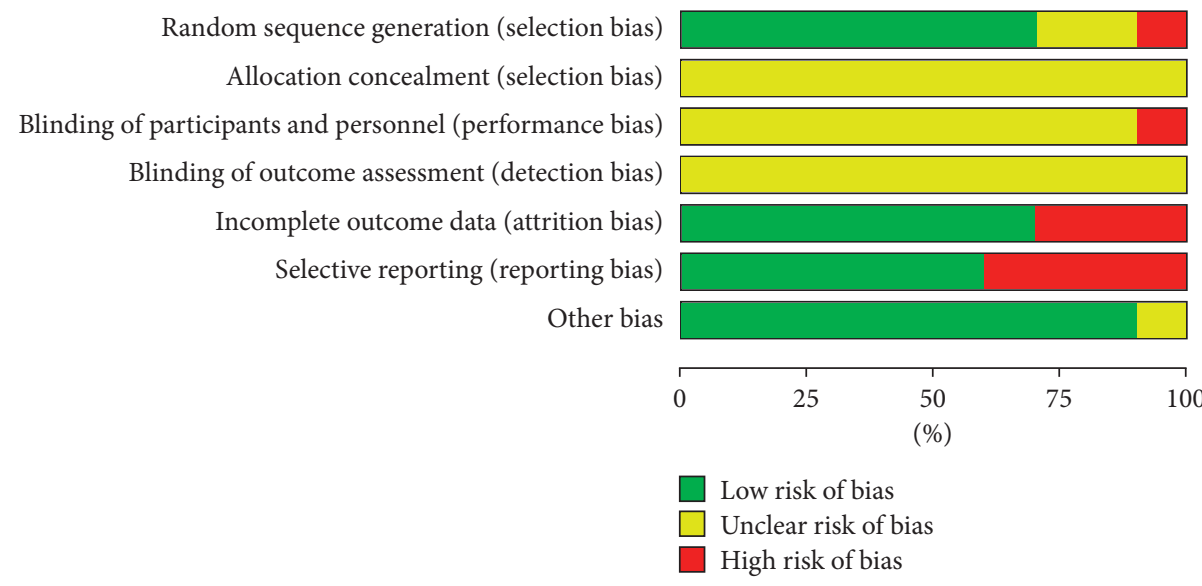

FIgURE 3: Risk-of-bias graph: a review of authors' judgments about each risk-of-bias item presented as percentages across all included studies.

not effective on the prosodic aspects of parkinsonian speech [16-18]. Over the years, speech and language pathologists presented various methods such as the SLTs to improve communication in PD patients [19]. The LSVT is a speech and language therapy method and one of the most widely used speech intervention methods in hypokinetic dysarthria associated with PD [20], wherein the patients are asked to produce a loud voice and focus their efforts on attaining, monitoring, and maintaining the loud voice. The objective of this meta-analysis was to evaluate the effectiveness of LSVT compared to other speech interventions or no treatment for PD patients with dysarthria.

During the past years, several studies investigated the effectiveness of LSVT on PD patients with dysarthria. To evaluate the effects of LSVT on dysphonia in patients with $\mathrm{PD}$, we analyzed the data from published RCTs. After strict screening, ten published articles were included in this study [21-30]. The meta-analysis of SPL from six trials $(n=211)$ and the VHI from four tests $(n=288)$ found LSVT to be more effective than other speech interventions or no treatment to improve vocal loudness and voice handicap. In addition, the follow-up results of SPL indicated long-term effects of LSVT and the LSVT improved UPDRS-III speech item score and speech intelligibility among the PD patients with dysphasia problems. In 2020, a consequence showed that compared with LSVT ARTICT, PD patients treated with LSVT showed more significant increases from baseline to posttreatment in transcription [31]. Furthermore, research has demonstrated that STN-DBS's impact on speech is variable and multifactorial, with most patients exhibiting a decline of speech intelligibility [32]. Jennifer Spielman further found that, compared with only LSVT or STN-DBS, several treated individuals with combination therapy had better significant clinical improvement in VHI scores and more variable long-term maintenance [10]. These findings proved that the LSVT had good responses and long-term effects than either other speech intervention, surgical operational, or no intervention. In addition, the long-term 


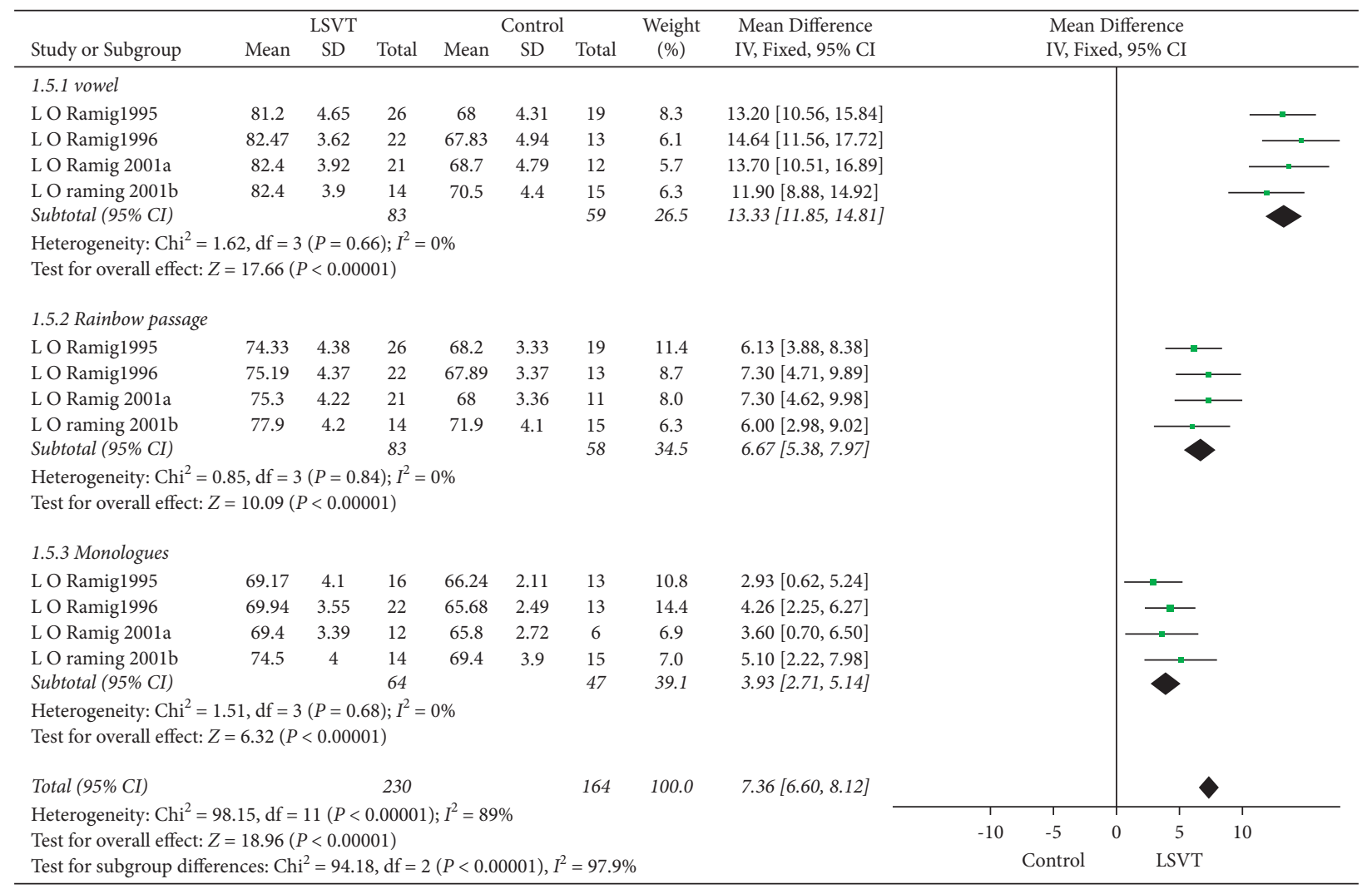

FIGURE 4: SPL immediately after the treatment during a reading of vowel, rainbow passage, and monologues.

\begin{tabular}{|c|c|c|c|c|c|c|c|c|c|c|c|c|}
\hline \multirow{3}{*}{$\begin{array}{l}\text { Study or Subgroup } \\
1.4 .1 \text { vowel }\end{array}$} & \multicolumn{3}{|c|}{ LSVT } & \multicolumn{3}{|c|}{ Control } & \multirow{2}{*}{$\begin{array}{l}\text { Weight } \\
(\%)\end{array}$} & \multirow{2}{*}{$\begin{array}{c}\text { Mean Difference } \\
\text { IV, Random, 95\% CI }\end{array}$} & \multirow{2}{*}{\multicolumn{4}{|c|}{$\begin{array}{c}\text { Mean Difference } \\
\text { IV, Random, 95\% CI }\end{array}$}} \\
\hline & \multirow[t]{2}{*}{ Mean } & \multirow[t]{2}{*}{$\mathrm{SD}$} & \multirow[t]{2}{*}{ Total } & \multirow[t]{2}{*}{ Mean } & \multirow[t]{2}{*}{ SD } & \multirow[t]{2}{*}{ Total } & & & & & & \\
\hline & & & & & & & & & & & & \\
\hline Geralyn Schulz 2021 & 79.4 & 3.85 & 20 & 71.9 & 3.66 & 18 & 12.3 & $7.50[5.11,9.89]$ & & & & - \\
\hline L O Ramig1996 & 77.58 & 4.41 & 22 & 68.2 & 6.04 & 13 & 9.7 & $9.38[5.61,13.15]$ & & & & \\
\hline L O raming $2001 \mathrm{~b}$ & 79.8 & 3.7 & 14 & 70.6 & 4.1 & 15 & 11.4 & $9.20[6.36,12.04]$ & & & & 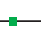 \\
\hline L O Raming 2018 & 79.8 & 10.6 & 22 & 76.1 & 8.3 & 22 & 6.7 & $3.70[-1.93,9.33]$ & & & & \\
\hline Subtotal (95\% CI) & & & 78 & & & 68 & 40.1 & $8.03[6.25,9.82]$ & & & & \\
\hline Heterogeneity: $\mathrm{Tau}^{2}=$ & $8 ; \mathrm{Chi}^{2}=$ & $3.61, c$ & $\mathrm{f}=3(H$ & $=0.31$; & $I^{2}=179$ & & & & & & & \\
\hline Test for overall effect: & $8.81(P$ & $<0.000$ & & & & & & & & & & \\
\hline 1.4.2 Rainbow Passage & & & & & & & & & & & & \\
\hline L O Ramig1996 & 70.3 & 3.5 & 22 & 67.25 & 3.97 & 13 & 11.9 & $3.05[0.44,5.66]$ & & & & \\
\hline L O raming $2001 \mathrm{~b}$ & 76.1 & 3.2 & 14 & 71.9 & 4.1 & 15 & 11.8 & $4.20[1.53,6.87]$ & & & & \\
\hline L O Raming 2018 & 76.8 & 6.2 & 22 & 71.3 & 4.8 & 22 & 10.6 & $5.50[2.22,8.78]$ & & & & \\
\hline Subtotal (95\% CI) & & & 58 & & & 50 & 34.2 & $4.07[2.45,5.69]$ & & & & \\
\hline Heterogeneity: $\mathrm{Tau}^{2}=$ & $0 ; \mathrm{Chi}^{2}=$ & $1.33, \mathrm{c}$ & $\mathrm{f}=2(P$ & $=0.51)$; & $2=0 \%$ & & & & & & & \\
\hline Test for overall effect: & $4.93(P$ & $<.000$ & & & & & & & & & & \\
\hline 1.4.3 Monologues & & & & & & & & & & & & \\
\hline L O Ramig1996 & 66.07 & 2.52 & 22 & 64.33 & 2.4 & 13 & 13.6 & $1.74[0.06,3.42]$ & & & 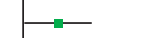 & \\
\hline L O raming $2001 \mathrm{~b}$ & 72.7 & 3.6 & 14 & 69.5 & 3.2 & 15 & 12.1 & $3.20[0.71,5.69]$ & & & & \\
\hline Subtotal (95\% CI) & & & 36 & & & 28 & 25.7 & $2.20[0.81,3.59]$ & & & & \\
\hline Heterogeneity: $\mathrm{Tau}^{2}=$ & $0 ; \mathrm{Chi}^{2}=$ & $0.91, c$ & $\mathrm{f}=1(F$ & $=0.34)$; & ${ }^{2}=0 \%$ & & & & & & & \\
\hline Test for overall effect: & $3.10(P$ & $=0.002$ & & & & & & & & & & \\
\hline Total (95\% CI) & & & 172 & & & 146 & 100.0 & $5.19[3.23,7.15]$ & & & & \\
\hline Heterogeneity: $\mathrm{Tau}^{2}=$ & $4 ; \mathrm{Chi}^{2}=$ & 36.16 , & $\mathrm{df}=8$ & $<0.000$ & 1); $I^{2}=$ & $78 \%$ & & & -10 & -5 & 0 & 10 \\
\hline $\begin{array}{l}\text { Test for overall effect: } \\
\text { Test for subgroup diff }\end{array}$ & $\begin{array}{l}5.19(P \\
\text { cces: Chi }\end{array}$ & $\begin{array}{l}0.000 \\
=25.6\end{array}$ & $\begin{array}{l}\text { 1) } \\
\text { 5, } \mathrm{df}=\end{array}$ & $(P<0.0$ & $001), 1$ & $=92.2 \%$ & & & -10 & Control & $\begin{array}{c}5 \\
\text { SVT }\end{array}$ & 10 \\
\hline
\end{tabular}

(a)

Figure 5: Continued. 


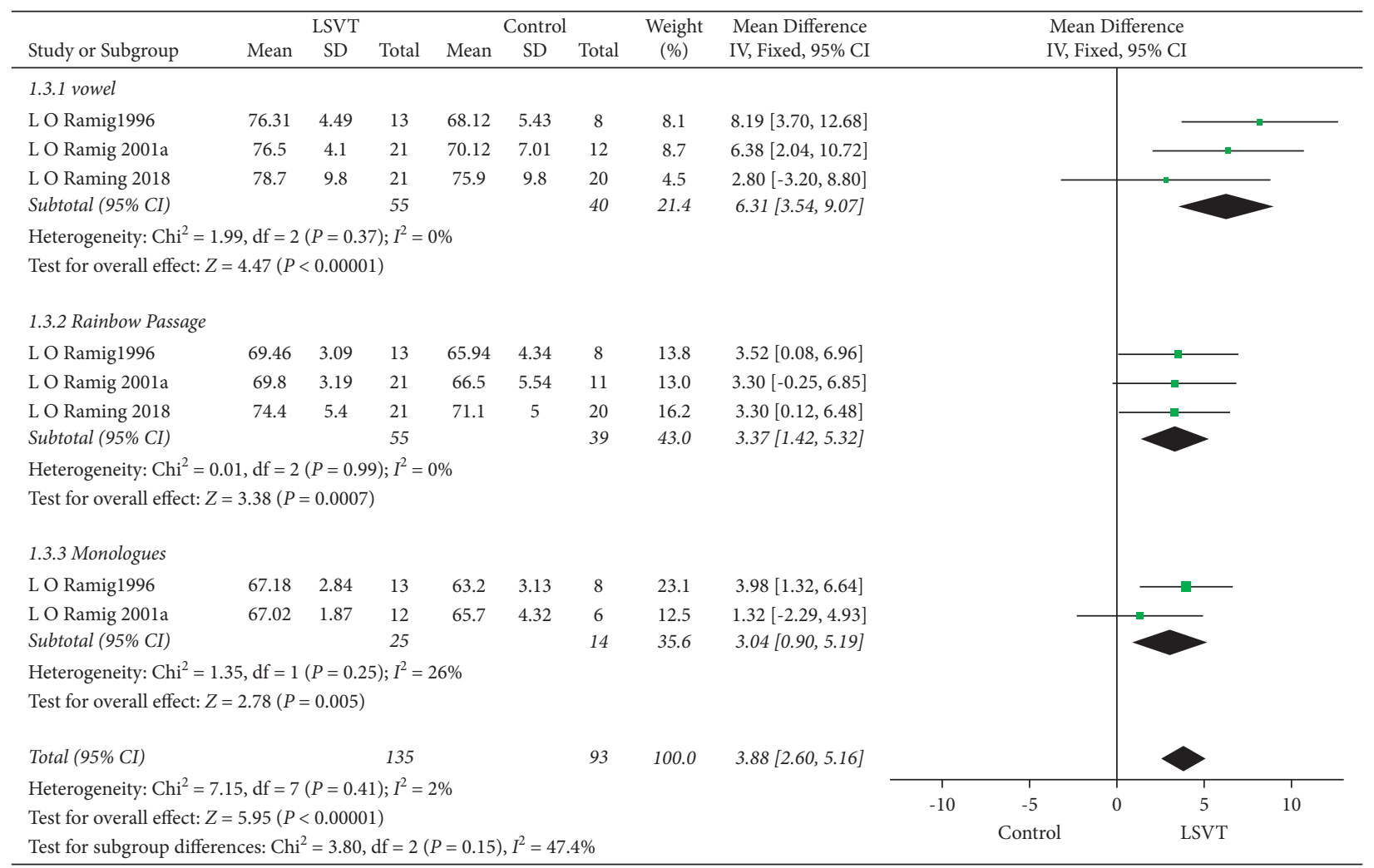

(b)

Figure 5: Forest plot showing mean difference and 95\% CI of SPL at different assessment times. (a) 1-6 months. (b) 6-12 months.

\begin{tabular}{|c|c|c|c|c|c|c|c|c|c|c|c|c|c|}
\hline \multirow{3}{*}{$\frac{\text { Study or Subgroup }}{\text { Arezoo Saffarian2019 }}$} & \multicolumn{3}{|c|}{ Experimental } & \multicolumn{3}{|c|}{ Control } & \multirow{3}{*}{$\begin{array}{c}\text { Weight } \\
(\%)\end{array}$} & \multirow{3}{*}{$\begin{array}{c}\text { Mean Difference } \\
\text { IV, Random, 95\% CI } \\
-26.77[-31.43,-22.11]\end{array}$} & \multirow{2}{*}{\multicolumn{5}{|c|}{$\begin{array}{c}\text { Mean Difference } \\
\text { IV, Random, 95\% CI }\end{array}$}} \\
\hline & \multirow{2}{*}{$\begin{array}{l}\text { Mean } \\
17.23\end{array}$} & \multirow{2}{*}{$\begin{array}{c}\mathrm{SD} \\
5.35\end{array}$} & \multirow{2}{*}{$\frac{\text { Total }}{13}$} & \multirow{2}{*}{$\frac{\text { Mean }}{44}$} & \multirow{2}{*}{$\frac{\mathrm{SD}}{5.88}$} & \multirow{2}{*}{$\frac{\text { Total }}{10}$} & & & & & & & \\
\hline & & & & & & & & & - & & & & \\
\hline Haiyu Tang 2016 & 58.32 & 16.58 & 32 & 68.23 & 20.86 & 32 & 20.3 & $-9.91[-19.14,-0.68]$ & & $\longrightarrow$ & & & \\
\hline Meifang Yang 2017 & 60.39 & 9.84 & 49 & 71.03 & 11.01 & 49 & 26.3 & $-10.64[-14.77,-6.51]$ & & $\longrightarrow$ & & & \\
\hline Qi Wu 2020 & 61.02 & 5.83 & 50 & 71.51 & 5.82 & 50 & 27.7 & $-10.49[-12.77,-8.21]$ & & - & & & \\
\hline Total $(95 \%$ CI) & & & 144 & & & 141 & 100.0 & $-14.60[-22.43,-6.77]$ & & & & & \\
\hline $\begin{array}{l}\text { Heterogeneity: } \mathrm{Tau}^{2}= \\
\text { Test for overall effect: }\end{array}$ & $\begin{array}{l}33 ; \mathrm{Chi}^{2} \\
3.66(P\end{array}$ & $\begin{array}{l}=39.82 \\
=0.000\end{array}$ & $\mathrm{df}=3$ & $<0.00$ & $001) ; I^{2}$ & $92 \%$ & & & $\begin{array}{l}1 \\
-20\end{array}$ & $\begin{array}{c}-10 \\
\text { LSVT }\end{array}$ & 0 & $\begin{array}{c}1 \\
10 \\
\text { Control }\end{array}$ & 20 \\
\hline
\end{tabular}

FIgURE 6: VHI after immediate treatment.

administration of dopamine in PD patients with the phonatory-prosodic subtype can stabilize the severity of speech disorder and improve speech performance [14]. The combined treatment of LSVT and levodopa remains to be explored.

A previous study by Yuan et al. evaluated the effectiveness of LSVT. There were some differences between the previous and current studies. The current meta-analysis included more studies compared to the study by Yuan et al. Moreover, some factors, such as the publication bias that might influence the meta-analysis results, were assessed in our study. In addition, the outcome indicators of the current study included SPL, VHI, STSD, and UPDRS-III speech item scores, but those in the study by Yuan et al. only included
SPL and VHI [33]. Despite these differences, we also found that the LSVT had good responses compared to either speech interventions or no intervention and had long-term effects, consistent with Yuan et al. study, suggesting the effectiveness of LSVT.

Nevertheless, the present meta-analysis has some limitations. First, we used stringent criteria for study inclusion and then performed data extraction and analysis. Heterogeneity was a significant issue while interpreting the results of the present meta-analysis. In the overall analysis of VHI after the treatment, we found high heterogeneity between the studies. We found high heterogeneity between the reflections in the comprehensive analysis of the UPDRS-III speech item score after the treatment. After leave-one-out sensitivity 


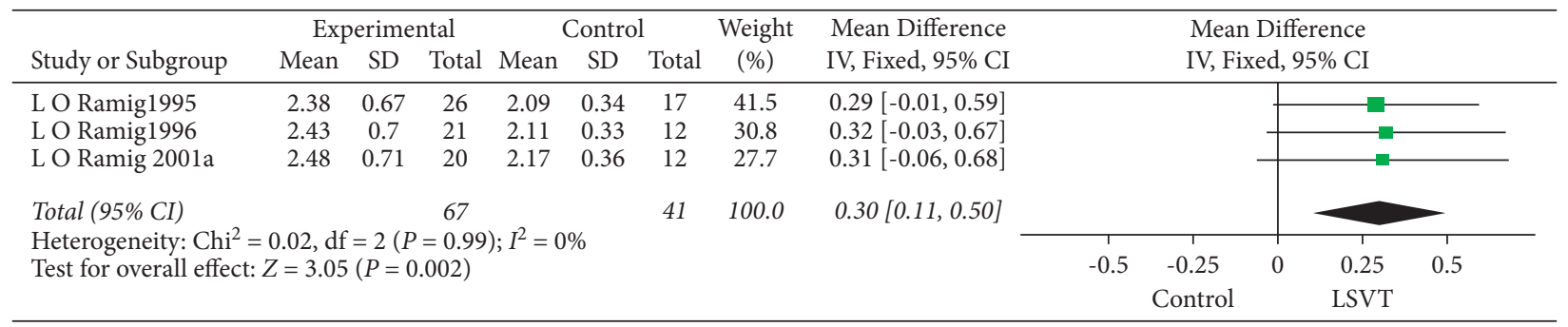

(a)

\begin{tabular}{|c|c|c|c|c|c|c|c|c|c|c|c|c|c|}
\hline \multirow[b]{2}{*}{ Study or Subgroup } & \multicolumn{3}{|c|}{ Experimental } & \multicolumn{3}{|c|}{ Control } & \multirow{2}{*}{$\begin{array}{l}\text { Weight } \\
(\%)\end{array}$} & \multirow{2}{*}{$\begin{array}{l}\text { Mean Difference } \\
\text { IV, Fixed, 95\% CI }\end{array}$} & \multirow{2}{*}{\multicolumn{5}{|c|}{$\begin{array}{l}\text { Mean Difference } \\
\text { IV, Fixed, 95\% CI }\end{array}$}} \\
\hline & Mean & $\mathrm{SD}$ & Total & Mean & $\mathrm{SD}$ & Total & & & & & & & \\
\hline L O Ramig1995 & 1.97 & 0.58 & 16 & 1.95 & 0.67 & 13 & 41.0 & $0.02[-0.44,0.48]$ & & & & & \\
\hline L O Ramig1996 & 2.09 & 0.55 & 13 & 1.93 & 0.64 & 9 & 33.1 & $0.16[-0.35,0.67]$ & & & & - & \\
\hline L O Ramig 2001a & 2.09 & 0.56 & 11 & 2.14 & 0.73 & 9 & 25.9 & $-0.05[-0.63,0.53]$ & & & & & \\
\hline Total $(95 \%$ CI) & & & 40 & & & 31 & 100.0 & $0.05[-0.25,0.34]$ & & & & & \\
\hline \multicolumn{9}{|c|}{$\begin{array}{l}\text { Heterogeneity: } \mathrm{Chi}^{2}=0.31, \mathrm{df}=2(P=0.86) ; I^{2}=0 \% \\
\text { Test for overall effect: } Z=0.32(P=0.75)\end{array}$} & -0.5 & $\begin{array}{c}-0.25 \\
\text { Control }\end{array}$ & 0 & $\begin{array}{c}0.25 \\
\text { LSVT }\end{array}$ & 0.5 \\
\hline
\end{tabular}

(b)

FIGURE 7: Forest plot showing mean difference and 95\% CI of STSD during rainbow passage (a) and monologues (b).

\begin{tabular}{|c|c|c|c|c|c|c|c|c|c|c|c|}
\hline \multirow{3}{*}{$\begin{array}{l}\text { Study or Subgroup } \\
\text { Haiyu Tang } 2016\end{array}$} & \multicolumn{3}{|c|}{ Experimental } & \multicolumn{3}{|c|}{ Control } & \multirow{2}{*}{$\begin{array}{c}\text { Weight } \\
(\%)\end{array}$} & \multirow{2}{*}{$\begin{array}{c}\text { Mean Difference } \\
\text { IV, Random, 95\% CI }\end{array}$} & \multirow{2}{*}{\multicolumn{3}{|c|}{$\begin{array}{c}\text { Mean Difference } \\
\text { IV, Random, 95\% CI }\end{array}$}} \\
\hline & Mean & SD & Total & Mean & SD & Total & & & & & \\
\hline & 1.43 & 0.37 & 32 & 2.25 & 0.32 & 32 & 39.8 & $-0.82[-0.99,-0.65]$ & $\leftarrow$ & & \\
\hline Meifang Yang 2017 & 1.39 & 0.61 & 49 & 1.82 & 0.82 & 49 & 32.6 & $-0.43[-0.72,-0.14]$ & & 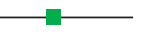 & \\
\hline Qi Wu 2020 & 1.66 & 1.08 & 50 & 2.04 & 0.78 & 50 & 27.6 & $-0.38[-0.75,-0.01]$ & & 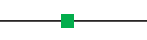 & \\
\hline Total (95\% CI) & & & 131 & & & 131 & 100.0 & $-0.57[-0.88,-0.26]$ & & & \\
\hline \multicolumn{8}{|c|}{$\begin{array}{l}\text { Heterogeneity: } \mathrm{Tau}^{2}=0.06 ; \mathrm{Chi}^{2}=8.08, \mathrm{df}= \\
\text { Test for overall effect: } Z=3.60(P=0.0003)\end{array}$} & & & $\begin{array}{rr}-0.5 & -0.25 \\
& \text { LSVT }\end{array}$ & $\begin{array}{cc}0 & 0.25 \\
& \text { Control }\end{array}$ \\
\hline
\end{tabular}

FIGURE 8: Forest plot showing mean difference and 95\% CI of UPDRS-III speech item score after immediate treatment.

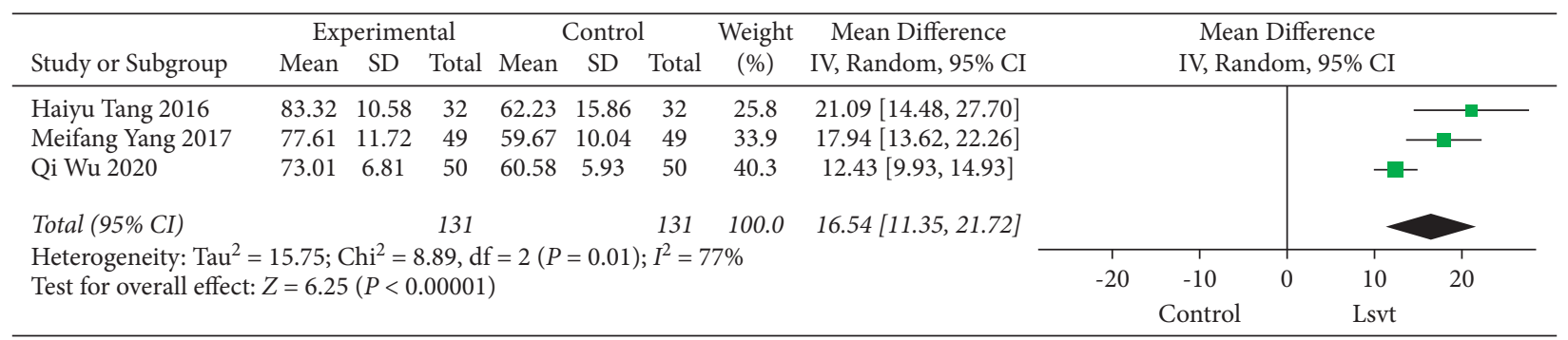

Figure 9: Forest plot showing mean difference and 95\% CI of speech intelligibility immediately treatment.

analyses, heterogeneity was removed after the exclusion of the study (Tang 2016). After investigation, the heterogeneity may be derived from systematic errors. Second, the participants in all studies were volunteers or recruited from outpatient clinics, support groups, and physicians motivated to improve their motor performance and were not the accurate representation of the broad population with PD. Third, although the included studies were highly consistent in methodology, differences may exist in relative effects on the meta-analysis results. To assess the impact of varying stages of disease progression on the effects of LSVT on dysarthria, we followed the Cochrane Handbook for Systematic Reviews of
Interventions to ensure the accuracy of the meta-analysis results. Nevertheless, we followed the Cochrane Handbook for Systematic Reviews of Interventions to ensure the accuracy of the meta-analysis results.

\section{Conclusion}

This study demonstrated the efficacy of LSVT in increasing vocal loudness and functional communication among individuals with PD. However, most studies included participants with mild-moderate PD. Additional RCTs with large sample sizes are required to validate the efficacy of 
LSVT in patients with different progression of $\mathrm{PD}$, including severe PD.

\section{Data Availability}

The data used to support the findings of this study are available from the corresponding author upon request.

\section{Conflicts of Interest}

The authors declare that they have no conflicts of interest.

\section{Authors' Contributions}

PTT designed and wrote the manuscript for XF. PTT, HM, and KXY screened the reference and extracted the data from the literature. WM and CXL accessed the basic information from the study. PTT and XF analyzed and interpreted the data. FXX and HM evaluated the quality of studies. $\mathrm{MH}$, WXC, and XF proofread the manuscript. Tingting Pu, Min Huang, and Xiangyu Kong contributed equally to the article.

\section{Acknowledgments}

This work was supported by the Chengdu Medical College Foundation (CYZ19-33), Chengdu Science and Technology Bureau Focused on Research and Development Support Plan (2019-YF09-00097-SN), the Popular Scientific Research Project of Sichuan Health Commission (20PJ171), and Sichuan Undergraduate Innovation and Startup Program Funding Support (S201913705080).

\section{References}

[1] C. W. Olanow, P. Calabresi, and J. A. Obeso, "Continuous dopaminergic stimulation as a treatment for Parkinson's disease: current status and future opportunities," Movement Disorders, vol. 35, no. 10, pp. 1731-1744, 2020.

[2] A. Reeve, E. Simcox, and D. Turnbull, "Ageing and Parkinson's disease: why is advancing age the biggest risk factor?" Ageing Research Reviews, vol. 14, no. 100, pp. 19-30, 2014.

[3] J. Jankovic, "Parkinson's disease: clinical features and diagnosis," Journal of Neurology \& Psychiatry, vol. 79, no. 4, pp. 368-376, 2008.

[4] S.-C. Hsu, Y. Jiao, M. J. McAuliffe et al., "Acoustic and perceptual speech characteristics of native Mandarin speakers with Parkinson's disease," Journal of the Acoustical Society of America, vol. 141, no. 3, pp. EL293-EL299, 2017.

[5] S. Yang, F. Wang, L. Yang et al., "The physical significance of acoustic parameters and its clinical significance of dysarthria in Parkinson's disease," Scientific Reports, vol. 10, no. 1, Article ID 11776, 2020.

[6] L. Q. Yang, X. L. Chen, Q. H. Guo et al., "Changes in facial expressions in patients with Parkinson's disease during the phonation test and their correlation with disease severity," Computer Speech \& Language, vol. 72, Article ID 101286, 2022.

[7] J. Yang, Q. Guo, X. Zou et al., "Correlation between head tremble and the severity of Parkinson's disease," CNS Neuroscience \& Therapeutics, vol. 17, no. 5, pp. 1-8, 2021.

[8] J. M. Barkmeier-Kraemer and H. M. Clark, "Speech-Language pathology evaluation and management of Hyperkinetic disorders affecting speech and swallowing function," Tremor and Other Hyperkinetic Movements (NY), vol. 7, no. 21, pp. 489-508, 2017.

[9] D. Aldridge, D. Theodoros, A. Angwin, and A. P. Vogel, "Speech outcomes in Parkinson's disease after subthalamic nucleus deep brain stimulation: a systematic review," Parkinsonism \& Related Disorders, vol. 9, no. 22, pp. 3-11, 2016.

[10] J. Spielman, L. Mahler, A. Halpern, P. Gilley, O. Klepitskaya, and L. Ramig, "Intensive voice treatment (LSVT ${ }^{\circledR}$ LOUD) for Parkinson's disease following deep brain stimulation of the subthalamic nucleus," Journal of Communication Disorders, vol. 44, no. 6, pp. 688-700, 2011.

[11] G. Le Dorze, L. Dionne, J. Ryalls, M. Julien, and L. Ouellet, "The effects of speech and language therapy for a case of dysarthria associated with Parkinson's disease," European Journal of Disorders of Communication, vol. 27, no. 4, pp. 313-324, 1992.

[12] W. J. Weiner and C. Singer, "Parkinson's disease and nonpharmacologic treatment programs," Journal of the American Geriatrics Society, vol. 37, no. 4, pp. 359-363, 1989.

[13] R. J. Wenke, P. Cornwell, and D. G. Theodoros, "Changes to articulation following LSVT(R) and traditional dysarthria therapy in non-progressive dysarthria," International Journal of Speech Language Pathology, vol. 12, no. 3, pp. 203-220, 2010.

[14] J. Rusz, T. Tykalova, M. Novotny et al., "Defining speech subtypes in De Novo Parkinson disease: response to longterm Levodopa therapy," Neurology, vol. 97, no. 21, pp. e2124-e2135, 2021.

[15] K. M. Smith and D. N. Caplan, "Communication impairment in Parkinson's disease: impact of motor and cognitive symptoms on speech and language," Brain and Language, vol. 185, no. 21, pp. 38-46, 2018.

[16] L. Azevedo, F. Cardoso, and C. Reis, “Análise acústica da prosódia emmulheres com doença de Parkinson: efeito da Levodopa," Arquivos de Neuro-Psiquiatria, vol. 61, no. 4, pp. 995-998, 2003.

[17] L. Azevedo, F. Cardoso, and C. Reis, "Análise acústica da prosódia emmulheres com doença de Parkinson: comparação com controles normais," Arquivos de Neuro-Psiquiatria, vol. 61, no. 4, pp. 999-1003, 2003.

[18] C. Atkinson-Clement, J. Sadat, and S. Pinto, "Behavioral treatments for speech in Parkinson's disease: meta-analyses and review of the literature," Neurodegenerative Disease Management, vol. 5, no. 3, pp. 233-248, 2015.

[19] E. C. de Angelis, L. F. Mourão, H. B. Ferraz, S. Behlau, P. A. Pontes, and L. A. Andrade, "Effect of voice rehabilitation on oral communication of Parkinson's disease patients," Acta Neurologica Scandinavica, vol. 96, no. 4, pp. 199-205, 1997.

[20] V. Martel Sauvageau, J.-P. Roy, M. Langlois, and J. Macoir, "Impact of the LSVT on vowel articulation and coarticulation in Parkinson's disease," Clinical Linguistics and Phonetics, vol. 29, no. 6, pp. 424-440, 2015.

[21] L. O. Ramig, S. Sapir, S. Countryman et al., "Intensive voice treatment (LSVT) for patients with Parkinson's disease: a 2 year follow up," Journal of Neurology Neurosurgery and Psychiatry, vol. 71, no. 4, pp. 493-498, 2001.

[22] L. O. Ramig, S. Countryman, L. L. Thompson, and Y. Horii, "Comparison of two forms of intensive speech treatment for Parkinson disease," Journal of Speech \& Hearing Research, vol. 38, no. 6, pp. 1232-1251, 1995.

[23] L. O. Ramig, S. Countryman, C. O’Brien, M. Hoehn, and L. Thompson, "Intensive speech treatment for patients with 
Parkinson's disease: short-and long-term comparison of two techniques," Neurology, vol. 47, no. 6, pp. 1496-1504, 1996.

[24] L. O. Ramig, S. Sapir, C. Fox, and S. Countryman, "Changes in vocal loudness following intensive voice treatment (LSVT) in individuals with Parkinson's disease: a comparison with untreated patients and normal age-matched controls," Movement Disorders, vol. 16, no. 1, pp. 79-83, 2001.

[25] L. Ramig, A. Halpern, J. Spielman, C. Fox, and K. Freeman, "Speech treatment in Parkinson's disease: randomized controlled trial (RCT)," Movement Disorders, vol. 33, no. 11, pp. 1777-1791, 2018.

[26] A. Saffarian, Y. Amiri Shavaki, G. Ali Shahidi, G. Hadavi, and Z. Jafari, "Lee Silverman voice treatment (LSVT) mitigates voice difficulties in mild Parkinson's disease," Medical Journal of the Islamic Republic of Iran, vol. 33, no. 13, pp. 1-6, 2019.

[27] H. Y. Tang, M. M. Xu, and H. Yu, "Effect of speech therapy with Lee Silverman voice treatment on speech function of Parkinson's disease patients," Journal of Nursing (China), vol. 23, no. 17, pp. 66-69, 2016.

[28] W. Qi, Z. Hongxia, J. Xiaolei, Y. Jiajia, L. Lingyan, and 1. Juan, "Application effect of stepped speech rehabilitation nursing in patients with Parkinson's disease," Journal of Anhui health vocational and Technical College, vol. 19, no. 2, pp. 63-67, 2020.

[29] Y. Meifang, Z. Jian, Q. Yaling, W. Jianxiong, and J. Mei, "Lee Silverman voice treatment can improve the speech and the life quality of patients with Parkinson's disease," Chinese Journal of Physical Medicine Rehabilitation, vol. 39, no. 1, pp. 43-47, 2017.

[30] G. Schulz, A. Halpern, J. Spielman et al., "Single word intelligibility of individuals with Parkinson's disease in noise: pre-specified secondary outcome variables from a randomized control trial (RCT) comparing two intensive speech treatments (LSVT LOUD vs. LSVT ARTIC)," Brain Sciences, vol. 11, no. 7, pp. 857-866, 2021.

[31] E. S. Levy, G. Moya-Galé, Y. H. M. Chang et al., "The effects of intensive speech treatment on intelligibility in Parkinson's disease: a randomised controlled trial," Clinical Medicine, vol. 24, Article ID 100429, 2020.

[32] E. Tripoliti, L. Zrinzo, I. Martinez-Torres et al., "Effects of subthalamic stimulation on speech of consecutive patients with Parkinson disease," Neurology, vol. 76, no. 1, pp. 80-86, 2011.

[33] F. Yuan, X. Guo, X. Wei et al., "Lee Silverman voice treatment for dysarthria in patients with Parkinson's disease: a systematic review and meta-analysis," European Journal of Neurology, vol. 27, no. 10, pp. 1957-1970, 2020. 